\title{
A Controlled Mixing Method for Stabilizing the Purity and Reducing the Waste in Gas Delivery Systems
}

\author{
Junsheng Wu, Farhang Shadman \\ Department of Chemical and Environmental Engineering, University of Arizona, Tucson, Arizona, USA \\ Email: junshengwu@email.arizona.edu,shadman@erc.arizona.edu
}

How to cite this paper: Wu, J.S. and Shadman, F. (2019) A Controlled Mixing Method for Stabilizing the Purity and Reducing the Waste in Gas Delivery Systems. Advances in Chemical Engineering and Science, 9, 11-26.

https://doi.org/10.4236/aces.2019.91002

Received: November 27, 2018

Accepted: December 23, 2018

Published: December 26, 2018

Copyright ( 92019 by authors and Scientific Research Publishing Inc. This work is licensed under the Creative Commons Attribution International License (CC BY 4.0).

http://creativecommons.org/licenses/by/4.0/

\section{Open Access}

\begin{abstract}
The variation of impurity concertation in the ultra-high purity (UHP) gases, delivered from cryogenic storage tanks and transported through long pipes, is a major problem in systems like those used in semiconductor manufacturing facilities. A method is developed for stabilizing the purity and reducing the gas consumption in these systems. This technique uses a dynamically controlled mixing of gases supplied by multiple cryogenic tanks. The control scheme uses software modules that simulate the processes that cause purity variation in both the cryogenic tanks and the transport lines. These processes include vaporization and supply in tanks, various modes of transport in delivery pipes, and the adsorption and desorption on surfaces. The method also includes and corrects for variations caused by transience in gas usage rate as well as ambient conditions.
\end{abstract}

\section{Keywords}

High-Purity Gases, Cryogenic, Impurity Drift, Moisture

\section{Introduction}

Ultra-high-purity (UHP) gases are widely used in semiconductor fabrication plants (fabs), both as reactants in some processes like deposition and etching [1] [2], and as inert gases for purging various parts of the system. For example, UHP nitrogen is used in very large quantities in semiconductor fabs as diluent and purge medium. The UHP gases are typically delivered through pipes from gas storage facilities outside the fab to the point of use (POU). UHP gases, such as nitrogen, are usually stored in the cryogenic tanks where gas is produced by controlled vaporization of the stored liquid and transported through delivery 
pipes to the fab. Most semiconductor processes are very sensitive to impurities and require a well-controlled quality [3] [4]. Failure to maintain a stable purity level at the (POU) can lower the performance of process tools and even slow or shut down the processing line [5].

Moisture, selected as the model impurity species in this study, is one of the most common impurities. While affecting many fabrication processes even at the parts per billion (ppb) levels, it is also one of the most challenging impurities to remove and control due to its strong adsorption on the surfaces of transport line, components, and reactors [3] [6] [7]. Additionally, when gases are supplied from cryogenic sources, there is usually some drift and variation in the moisture level at the POU due to two major factors [8]:

1) Source drift: This is caused by the build-up of moisture in the cryogenic tanks due to the selective retention of moisture in the liquid phase during vaporization. As impurity level goes up with time and gas usage, and the gas purity can no longer satisfy the process requirements (usually after $70 \%-80 \%$ of a tank is used), the remaining content is rejected and wasted, causing financial and environmental losses.

2) Temperature-induced variations: This is caused by adsorption (capture) and desorption (release) of moisture on the surfaces of delivery pipes and flow-control devices. The delivery pipes in most fabs are long and therefore a major sink for moisture adsorption. Moreover, these pipes, running from the storage area to the POU are usually in the open environment. Therefore, ambient temperature variations would have a large effect on the moisture adsorption and desorption, leading to drifts and spikes in impurity at the POU.

Single tank systems are widely used as cryogenic sources for many gases in industry today. However, this configuration results in impurity drift due to selective retention and accumulation of impurities in one phase during vaporization. For example, moisture is selectively retained in the liquid phase of most inert and process gas tanks, resulting in impurity drift upward, as liquid is vaporized and gas is withdrawn from the cryogenic tank. The drift necessitates shutting down the supply when the impurity level reaches the highest acceptable level. At this time, the partially used tank needs to be returned to the supplier, often with large amount of gas remaining unused in the tank. This increases the cost and the negative environmental impact of the operation due to the partial usage of tank content.

In recent years, some modifications have been introduced in cryogenic tank design to reduce the effect of source drift [9]. These changes increase the cost and the complications of supply tanks significantly. However, there has been no systematic study of disturbances caused by pipelines or developments of techniques to mitigate them. Purifiers can be used to remove moisture at the POU [1]; however, they are expensive and often unreliable under transient flow conditions. A previous study by our group focused on some preliminary study of the effect of pipeline geometry and temperature variations on the moisture level at 
the POU [10]. The objective of the current work has been to develop a method for mitigating the effects of the variations in impurity levels, caused by the above two factors and assuring a stable and well-controlled purity level at the POU.

\section{Method of Approach}

The proposed concept and the associated system in this study are schematically shown in Figure 1. The system, chosen to illustrate the method, consists of two cryogenic tanks, two mass flow controllers (MFC), a gas delivery system, a real-time sensor for on-line measurement of impurities, and the auxiliary electronics for running the process simulator, data acquisition, and MFCs programing and control. The flow streams from the two tanks are controlled by two MFCs, then mixed and transported to the POU through a transport pipeline. The impurity level at the POU is monitored by an online sensor. The process simulator provides input to the MFC controller unit that adjusts the flow out of each MFC. Overall, the set-up provides a dynamic flow-mixing scheme run by the output from the process simulator. The system properties, operating conditions and purity requirements are all inputs to the process simulator. The details of the process simulator and its functions are described in the following two sections: first one for cancelling the drift in the cryogenic tanks and the second one for mitigating the effects of the pipeline temperature variations.

\subsection{Multiple Tanks to Resolve the Source Drift Problem}

As pointed out in the Introduction section, the single-tank configuration results in impurity drift due to the accumulation of impurities like moisture in the liquid phase during vaporization. This leads to partial usage of tank content and wasting of gas. To resolve this drift issue, a dual tank system is proposed, where flow rates from two tanks are varied and mixed so that a stable and well-controlled purity level is obtained.

Assuming that gas and liquid in the tank are in equilibrium, the following equations determine the operation of tank 1 :

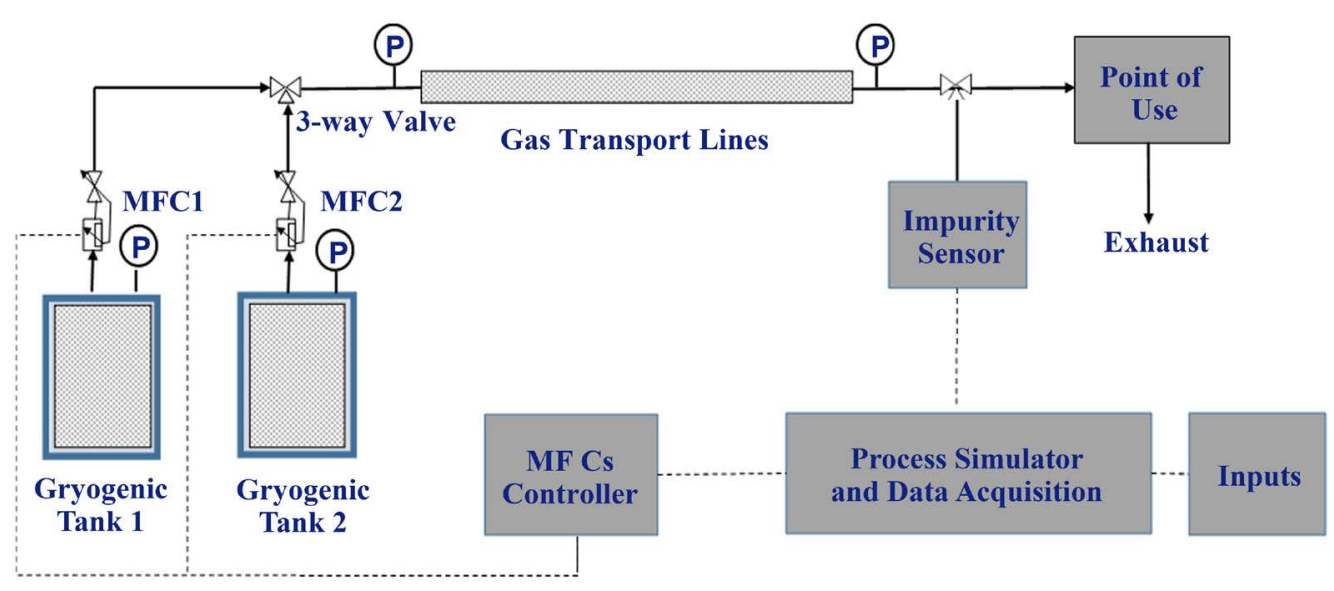

Figure 1. Schematic of proposed system. 


$$
\begin{gathered}
V_{g 1}+V_{l 1}=V_{t 1} \\
C_{t 1} V_{g 1}+C_{l 1} V_{l 1}=M_{1} \\
-\frac{\mathrm{d} M_{1}}{\mathrm{~d} t}=C_{t 1} Q \\
Y_{g 1}=Y_{l 1} H \\
-\frac{\mathrm{d} V_{l 1}}{\mathrm{~d} t} \alpha=\frac{\mathrm{d} V_{g 1}}{\mathrm{~d} t}+Q,
\end{gathered}
$$

where $V_{t 1}, V_{g 1}$, and $V_{l 1}$ are the total tank volume, the gas phase volume, and the liquid phase volume in the tank, respectively. $C_{t 1}$ and $C_{l 1}$ are the impurity concentrations in the vapor and liquid phases in the tank, $M_{1}$ is the total amount of impurity in the tank, $Q$ is the withdrawn flow rate, $Y_{g 1}$ and $Y_{l 1}$ are the mole fractions of impurity in the vapor and the liquid phases, $H$ is Henry's law constant, and $\alpha$ is the ratio of liquid to vapor densities. Equations (2) and (3) together are the mass balance for the impurity in the tank; Equation (4) shows the liquid-vapor equilibrium for the impurity, and Equation (5) is the overall balance for gaseous content. Solving these five equations simultaneously gives:

$$
\begin{gathered}
\frac{\mathrm{d} V_{g 1}}{\mathrm{~d} t}=\frac{Q}{\alpha} \\
\frac{\mathrm{d} C_{t 1}}{\mathrm{~d} t}=\frac{Q(1-H) C_{t 1}}{\alpha V_{l 1}} .
\end{gathered}
$$

The total flow rate, $Q$, which is the sum of the flow rates from the tanks is given by the process demand at the POU. The flow rate from the first tank, $Q_{1}$, as a fraction of $Q$, is given by:

$$
Q_{1}=b Q .
$$

Equations (6) and (7) can be modified as

$$
\begin{gathered}
\frac{\mathrm{d} V_{g 1}}{\mathrm{~d} t}=\frac{b Q}{\alpha} \\
\frac{\mathrm{d} C_{t 1}}{\mathrm{~d} t}=\frac{b Q(1-H) C_{t 1}}{\alpha V_{l 1}} .
\end{gathered}
$$

Similarly, the equations in tank 2 are

$$
\begin{gathered}
\frac{\mathrm{d} V_{g 2}}{\mathrm{~d} t}=\frac{(1-b) Q}{\alpha} \\
\frac{\mathrm{d} C_{t 2}}{\mathrm{~d} t}=\frac{(1-b) Q(1-H) C_{t 2}}{\alpha V_{l 2}} .
\end{gathered}
$$

The impurity concentration in the mixed flow from two tanks is

$$
C_{t}=b C_{t 1}+(1-b) C_{t 2} .
$$

Given any desired $C_{t}(t)$ function, the mixing function, $b(t)$, is given by:

$$
b=\frac{C_{t}-C_{t 2}}{C_{t 1}-C_{t 2}} .
$$




\subsection{Programmed Mixing to Mitigate the Temperature-Induced Variations}

The analysis of the processes taking place in the pipeline is through solving the conservation equations of transport and reactions in the pipe. However, application of the conventional numerical approach in this particular case is complicated since the inlet concentration is not known; the known boundary condition is the outlet and not the inlet concentration. The proposed solution to this numerical issue is the use of an equivalent system model consisting of a series of well-mixed cell, shown in Figure 2, where the number of cells is selected to represent the extent of dispersion in the pipe. This modeling approach is widely used in the analysis of non-ideal tubular reactors [11].

The mass balance for impurity in the gas phase for the first cell is given by

$$
C_{i n}-C_{1}+\frac{S}{Q}\left[k_{d} C_{s 1}-k_{a} C_{1}\left(S_{0}-C_{s 1}\right)\right]=\frac{V}{Q} \frac{\mathrm{d} C_{1}}{\mathrm{~d} t}
$$

The mass balance for any intermediate cell $i$ in the chain is

$$
C_{i-1}-C_{i}+\frac{S}{Q}\left[k_{d} C_{s i}-k_{a} C_{i}\left(S_{0}-C_{s i}\right)\right]=\frac{V}{Q} \frac{\mathrm{d} C_{i}}{\mathrm{~d} t}
$$

and the corresponding equation for the last cell is

$$
C_{f-1}-C_{f}+\frac{S}{Q}\left[k_{d} C_{s f}-k_{a} C_{f}\left(S_{0}-C_{s f}\right)\right]=\frac{V}{Q} \frac{\mathrm{d} C_{f}}{\mathrm{~d} t}
$$

The mass balance equations for the impurity adsorbed on the pipe surface are

$$
\begin{gathered}
k_{a} C_{1}\left(S_{0}-C_{s 1}\right)-k_{d} C_{s 1}=\frac{\mathrm{d} C_{s 1}}{\mathrm{~d} t} \\
k_{a} C_{i}\left(S_{0}-C_{s i}\right)-k_{d} C_{s i}=\frac{\mathrm{d} C_{s i}}{\mathrm{~d} t} \text { for any cell } i \text { in the chain } \\
k_{a} C_{f}\left(S_{0}-C_{s f}\right)-k_{d} C_{s f}=\frac{\mathrm{d} C_{s f}}{\mathrm{~d} t}
\end{gathered}
$$

where $C_{i n}$ and $C_{1}$ are the inlet and the outlet impurity concentrations of the first cell; $C_{i-1}$ and $C_{i}$ are the inlet and the outlet impurity concentrations of cell $i$; similarly, $C_{f-1}$ and $C_{f}$ are the inlet and outlet impurity concentrations of the last cell. $C_{s 1}, C_{s i}$, and $C_{s f}$ are the adsorbed concentrations in these cells; $k_{a}$ is the adsorption rate constant, $k_{d}$ is the desorption rate constant, and $S_{0}$ is the surface site density in each cell; $S$ is the surface area of each cell, $V$ is the cell volume, and $Q$ is the total volumetric flow rate.

The initial conditions of Equations (15) to (20) are

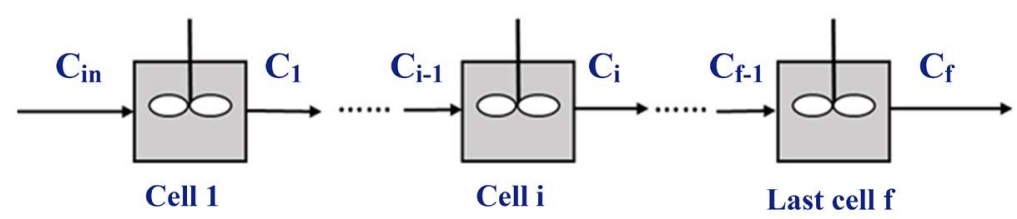

Figure 2. Schematic of mixing cells model. 


$$
\begin{gathered}
\text { at } t=0, C_{s 1}=C_{s i}=C_{s f}=C_{s 0} \\
\text { at } t=0, C_{i n}=C_{1}=C_{i-1}=C_{i}=C_{f-1}=C_{f}=C_{0},
\end{gathered}
$$

where $C_{s 0}$ is the initial adsorbed concentration, $C_{0}$ is the initial gas phase concentration, and $C_{s 0}$ is the adsorbed concentration in equilibrium with $C_{0}$.

The adsorption rate constant, $k_{a}$, and the desorption rate constant, $k_{d}$, are functions of temperature, given by

$$
\begin{aligned}
& k_{a} \propto \mathrm{e}^{\frac{-E_{a}}{R T_{a}}} \\
& k_{d} \propto \mathrm{e}^{\frac{-E_{d}}{R T_{a}}},
\end{aligned}
$$

where $E_{a}$ and $E_{d}$ are the activation energies for adsorption and desorption, $R$ is gas constant, and $T_{a}$ is ambient temperature in the pipe.

When the mixed flow enters the pipe, its temperature rises from tank temperature, $T_{t}$, to the pipe temperature which is assumed to be the ambient temperature, $T_{a}$. Therefore, the mixed concentration, $C_{t}$, is related to the inlet concentration of cell $1, C_{i n}$, by

$$
C_{i n}=C_{t} \frac{T_{t}}{T_{a}}
$$

and the change in the outlet concentration of the last cell, $C_{f}$, with temperature is given by

$$
C_{f}=C_{0} \frac{T_{0}}{T_{a}},
$$

where $T_{0}$ is the initial temperature in the pipe.

For a given desired $C_{f}$, the function $b(t)$, which is the ratio of flow rate from tank 1 to the total flow rate, is determined by the simultaneous solution to the above equations.

\section{Results and Discussion}

\subsection{Two-Tank Configuration for Canceling the Impurity Drift}

Nitrogen and moisture are selected as the model main gas and impurity, respectively in this example. However, the methodology and the process simulator tool are not limited to these two compounds and can be applied to other gases as well. In this example, two tanks are used simultaneously as the cryogenic source for nitrogen. Initially, tank 1 is a partially used and tank 2 is a new full tank. Since the typical gas usage in semiconductor processing tools is transient and periodic, a cyclic flow rate is used to represent the total gas supplied by the system.

In general, the present analysis can be used to determine the mixing function $b(t)$ needed for obtaining any desired impurity concentration in the mixed flow from the cryogenic tanks, $C_{t}(t)$. In this example, the desired concentration, $C_{t}(t)$, is assumed to be constant. The parameters used in this example are given in Table 1. Henry's law constant of 0.39 was calculated 
Table 1. Parameters in two-tank model study.

\begin{tabular}{ccc}
\hline Parameter & Definition & Value \\
\hline$a$ & Ratio of liquid to vapor densities & 41.77 \\
$H$ & Henry's law constant & 0.39 \\
$V_{l 10}$ & Initial liquid volume in tank 1 & $12 \mathrm{~m}^{3}$ \\
$V_{l 20}$ & Initial liquid volume in tank 2 & $30 \mathrm{~m}^{3}$ \\
$Q_{h}$ & High flow rate & $0.0199 \mathrm{~m}^{3} / \mathrm{s}$ \\
$Q_{l}$ & Low flow rate & $1.99 \mathrm{E}-3 \mathrm{~m}^{3} / \mathrm{s}$ \\
$t_{h}$ & Running time for high flow rate & $20 \mathrm{~min}$ \\
$t_{l}$ & Running time for low flow rate & $60 \mathrm{~min}$ \\
$V_{t}$ & Total tank volume & $30 \mathrm{~m}^{3}$ \\
$C_{t 10}$ & Initial moisture concentration in tank 1 vapor & $35 \mathrm{ppb}$ \\
$C_{t 20}$ & Initial moisture concentration in tank 2 vapor & $20 \mathrm{ppb}$ \\
$C_{t}(t)$ & Mixed concentration & $35 \mathrm{ppb}$ \\
\hline
\end{tabular}

from experimental data presented in previous study [10]. It is assumed that the flow rate needed at the POU alternates between a low value and a high value at regular intervals. This kind of variation is typical for most semiconductor fabrication applications and tools. Using the analysis method of Section 2.1, the mixing function, $b(t)$, that gives a constant mixed concentration $C_{t}(t)=35 \mathrm{ppb}$, is determined; the results are shown in Figure 3.

The mixing function profile shows that initially $b(t)=1$, indicating that the mixed flow is fully supplied from tank 1 . As time goes on, $b(t)$ decreases because the moisture level in tank 1 increases and more flow from tank 2 is required to compensate for this increase. After about 44 hours, $b(t)$ is nearly zero, indicating that the mixed flow is almost provided from tank 2 . At this time, moisture level in tank 1 is too high and the desired mixed concentration cannot be obtained by mixing the flow from these two tanks. Therefore, a tank change is needed at this time to replace the exhausted tank 1 with a new tank.

Figure 4 shows liquid volume in two tanks during this 44 -hour cycle before tank replacement. At the end of this cycle, the liquid volume in tank 2 decreases from $30 \mathrm{~m}^{3}$ to $12.1 \mathrm{~m}^{3}$, which is almost the same volume as the initial liquid volume $\left(12 \mathrm{~m}^{3}\right)$ in tank 1 . The liquid volume in tank 1 goes from $12 \mathrm{~m}^{3}$ to $2.4 \mathrm{~m}^{3}$ after 44 hours. The 44-hour cycle represents the lifetime of tank 1 before replacing it with a new tank. At this time, tank 2 is in conditions similar to that of tank 1 at the beginning of the cycle. Therefore, a new cycle starts and repeats the same changes. After each cycle, the tank which runs out of liquid nitrogen will be taken out for recharge or replacement.

To illustrate the advantages of the proposed system configuration in comparison with a typical conventional supply system, the time profiles of impurity in both cases are shown in Figure 5. In the conventional single-tank system, a stabilized moisture level is not achievable, and the impurity concentration goes up with 


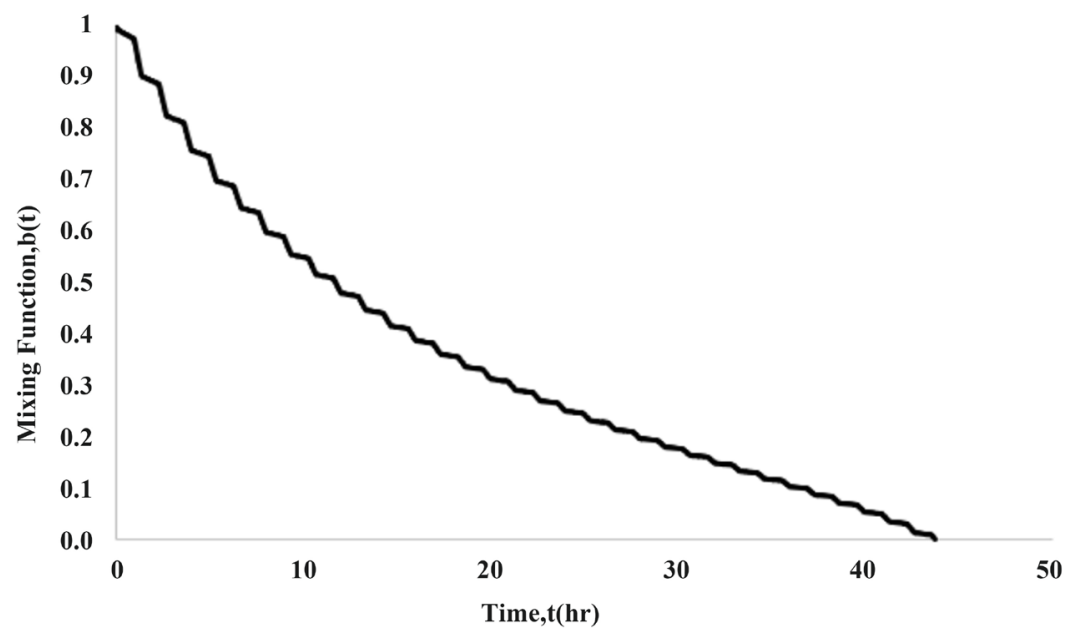

Figure 3. Temporal profile of the mixing function, $b(t)$.

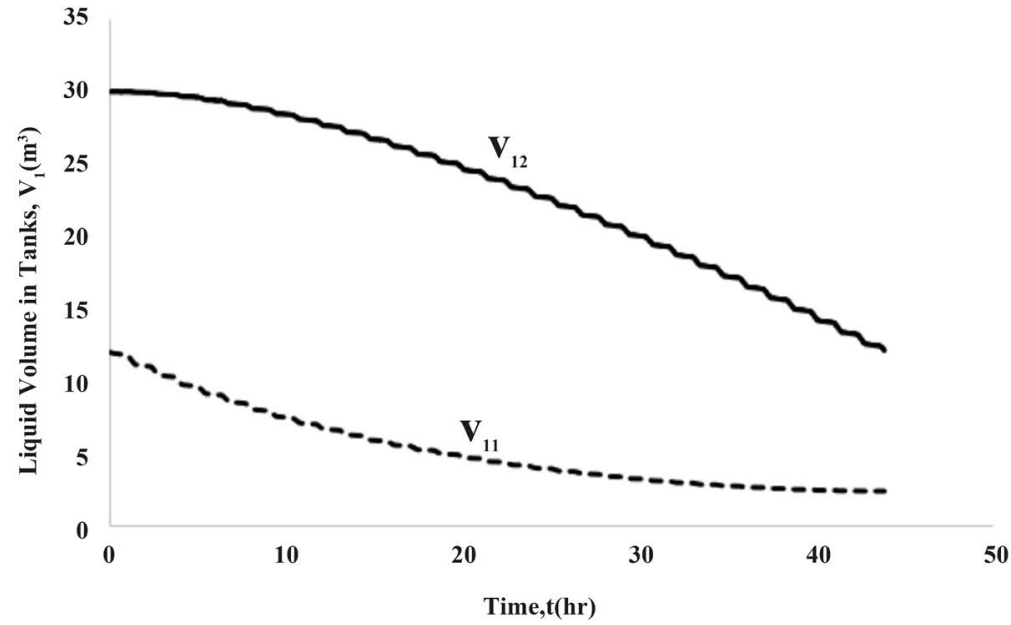

Figure 4. Temporal profiles of the liquid content of the two tanks.

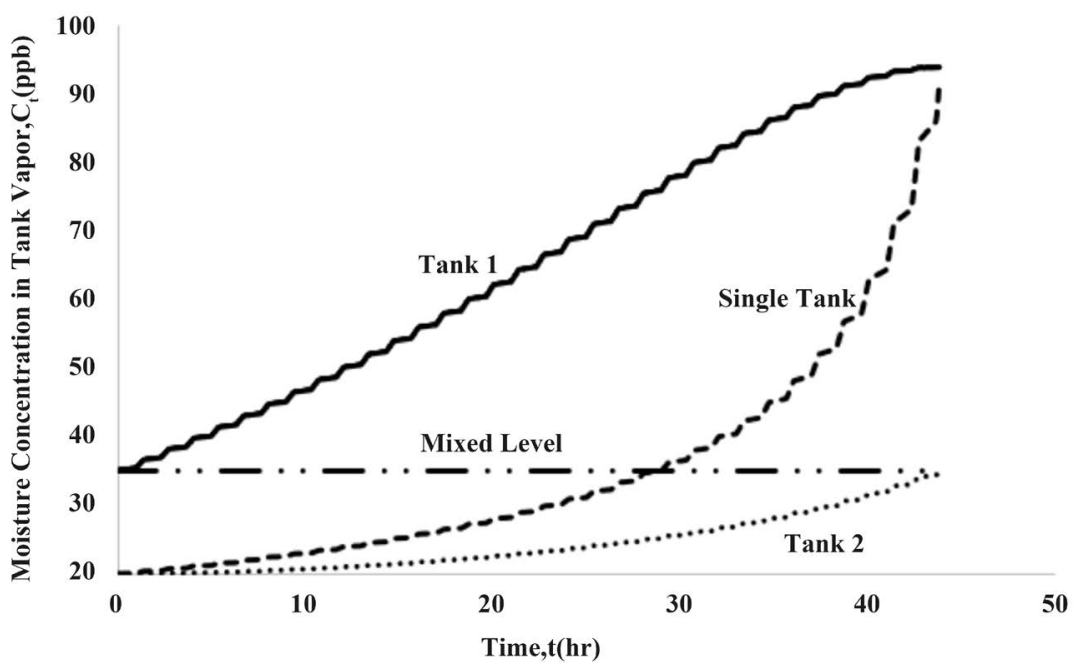

Figure 5. Comparison of the impurity profiles in two-tank and single-tank configurations. 
time; after around 28 hours, the moisture level exceeds $35 \mathrm{ppb}$. However, using the proposed controlled mixing with the appropriate mixing function, $b(t)=1$, a stream with constant concentration of $35 \mathrm{ppb}$ is obtained and maintained for the entire cycle time. Moreover, the results show that the two-tank configuration with the proposed mixing technique results in $92 \%$ usage of the liquid nitrogen in each tank compared with less than $80 \%$ usage of liquid nitrogen in a conventional single-tank system.

\subsection{Application of the Proposed Scheme to Cancel the Combined Effects of Tank Drift and Pipe Temperature Variations}

In this example, a more complete system is analyzed, where the delivery tanks are followed by a pipeline that takes the gas from the tanks to the POU. Therefore, the transport processes, the adsorption and desorption effects, and the temperature changes in the ambient around the pipe all contribute to the impurity variations at the POU. For illustration, a desired constant moisture level of 40 $\mathrm{ppb}$ is assumed at the POU, which is the pipe outlet in this case. A cyclic flow rate between a high value $Q_{h}$ and a low value $Q_{l}$ is used to represent the POU requirement. In one cycle, $Q_{h}$ lasts 20 minutes, and $Q_{l}$ lasts 60 minutes. The cyclic ambient temperature (diurnal effect) is assumed to follow:

$$
T_{a}=298+15 \sin \left(\frac{\pi}{12}(t[\mathrm{hr}]+12)\right)[\mathrm{K}] .
$$

The initial moisture concentration $C_{0}$ is $7.79 \mathrm{E}-6 \mathrm{~mol} / \mathrm{m}^{3}$; therefore, the desired concentration at $\mathrm{POU}$ is:

$$
C_{f}=\left(7.79 E^{-6}\left[\mathrm{~mol} / \mathrm{m}^{3}\right]\right) * \frac{298[\mathrm{~K}]}{15 \sin \left(\frac{\pi}{12}(t[\mathrm{hr}]+12)\right)[\mathrm{K}]}
$$

The mixing function $b(t)$ is calculated in two steps. In the first step, the inlet concentration, $C_{i n}$, is determined using the mixing cells model described in Section 2.2. The parameters of the system used in this example are listed in Table 2.

In the first step, the pipe inlet concentration, $C_{i n}$, is calculated from the mixing cells model of Section 2.2. $C_{i n}$ starts as $C_{0}$ and then changes due to temperature variations, going down as temperature goes up. The comparison of results for 3 and 4 tanks in Figure 6 shows that there is not a significant difference in the final results between these two cases.

In the second step, the procedure described in Section 2.1 is used to find $b(t)$ from $C_{i n}$, calculated in step 1. Due to the presence of the pipeline, the system configuration in this case is different from that of example in Section 3.1; therefore, the resulting mixing function, $b(t)$, will also be different.

In this example, the cycle starts with one tank initially full and one tank with $1 / 3$ liquid nitrogen remaining. The used tank is called tank 1 , and the full tank is labeled tank 2 . Tank 1 starts with the moisture level of $40 \mathrm{ppb}$, which is the same as the initial moisture level in the delivery pipe. The flow from tank 2 has the initial moisture level of $20 \mathrm{ppb}$. Using $C_{i n}$, obtained from the analysis of the pipe 
Table 2. Parameters in combination of models.

\begin{tabular}{ccc}
\hline Parameter & Definition & Value \\
\hline$E_{a}$ & Activation energy of adsorption & $5 \mathrm{kcal} / \mathrm{mol}$ \\
$E_{d}$ & Activation energy of desorption & $30 \mathrm{kcal} / \mathrm{mol}$ \\
$k_{a 0}$ & Adsorption rate constant at $298 \mathrm{~K}$ & $5 \mathrm{~m}^{3} / \mathrm{mol} \cdot \mathrm{s}$ \\
$k_{d 0}$ & Desorption rate constant at $298 \mathrm{~K}$ & $5 \mathrm{E}-51 / \mathrm{s}$ \\
$S_{0}$ & Surface site density & $1.5 \mathrm{E}-8 \mathrm{~mol} / \mathrm{m}^{2}$ \\
$L_{2}$ & Pipe length & $100 \mathrm{~m}$ \\
$d$ & Pipe diameter & $0.1 \mathrm{~m}$ \\
$P$ & Pressure & $4.83 \mathrm{E} 5 \mathrm{~Pa}$ \\
$Q_{h}$ & High flow rate & $9.93 \mathrm{E}-3 \mathrm{~m}{ }^{3} / \mathrm{s}$ \\
$Q_{l}$ & Low flow rate & $9.93 \mathrm{E}-5 \mathrm{~m}{ }^{3} / \mathrm{s}$ \\
$C_{0}$ & Initial moisture concentration & $7.79 \mathrm{E}-6 \mathrm{~mol} / \mathrm{m}^{3}$ \\
$C_{t 10}$ & Initial moisture concentration in tank 1 vapor & $40 \mathrm{ppb}$ \\
$C_{t 20}$ & Initial moisture concentration in tank 2 vapor & $20 \mathrm{ppb}$ \\
$V_{l 10}$ & Initial liquid volume in tank 1 & $9.65 \mathrm{~m}{ }^{3}$ \\
$V_{l 20}$ & Initial liquid volume in tank 2 & $30 \mathrm{~m}^{3}$ \\
\hline & & \\
\hline & & \\
\hline
\end{tabular}

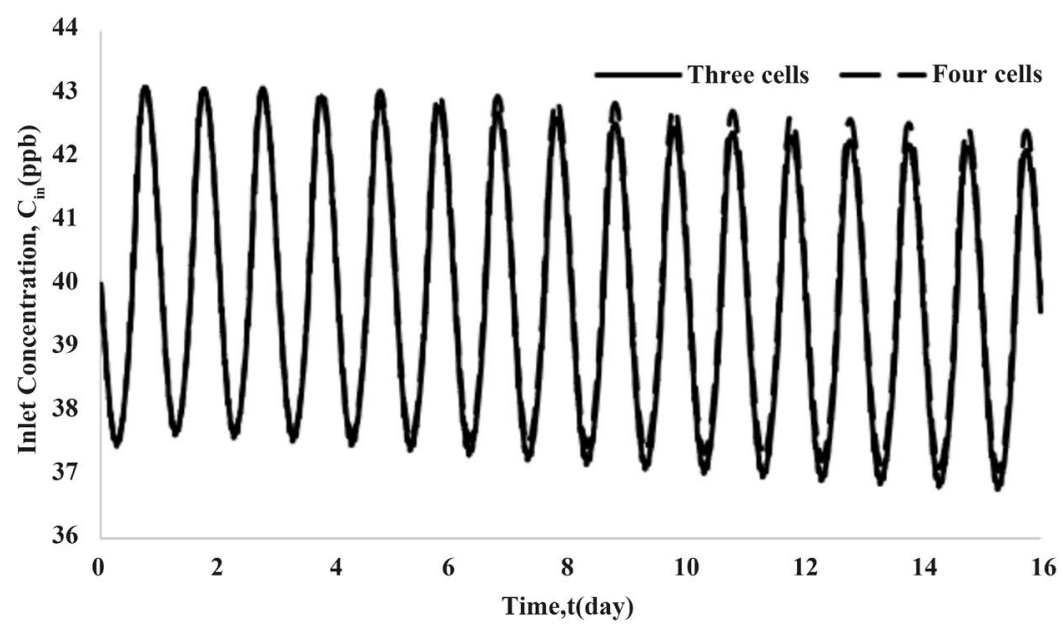

Figure 6. Comparison of $C_{i n}$ profiles obtained by assuming 3 and 4 cells in modeling the pipeline.

model, $C_{t}(t)$ is calculated using Equation (25). The calculated mixing function, $b(t)$, and the liquid volume in tanks are shown in Figure 7 and Figure 8. The results show that at the end of 16 days, $b$ is nearly zero. The liquid volume in tank 2 drops from $30 \mathrm{~m}^{3}$ to $9.77 \mathrm{~m}^{3}$, which is close to the initial liquid volume $\left(9.65 \mathrm{~m}^{3}\right)$ in tank 1. During this time, the liquid volume in tank 1 goes from 9.65 $\mathrm{m}^{3}$ to $0.80 \mathrm{~m}^{3}$ after 16 days. Therefore, 16 days represents one cycle and the time for replacement of the exhaust tank. Around 97\% of liquid nitrogen will be used after one cycle, which represents a much better usage efficiency than that from 


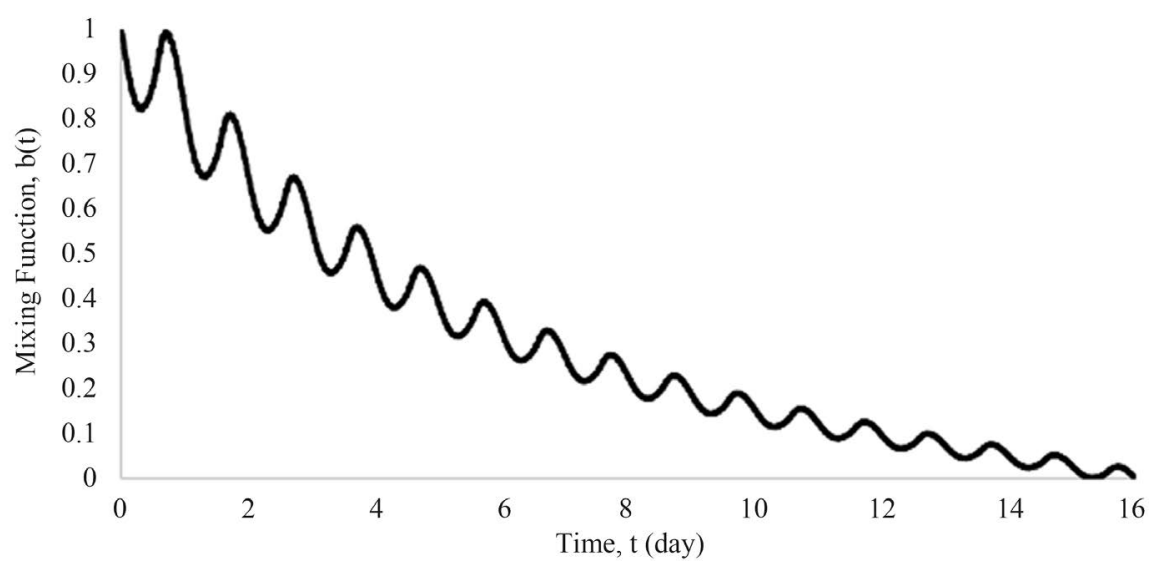

Figure 7. Temporal profile of the mixing function, $b(t)$.

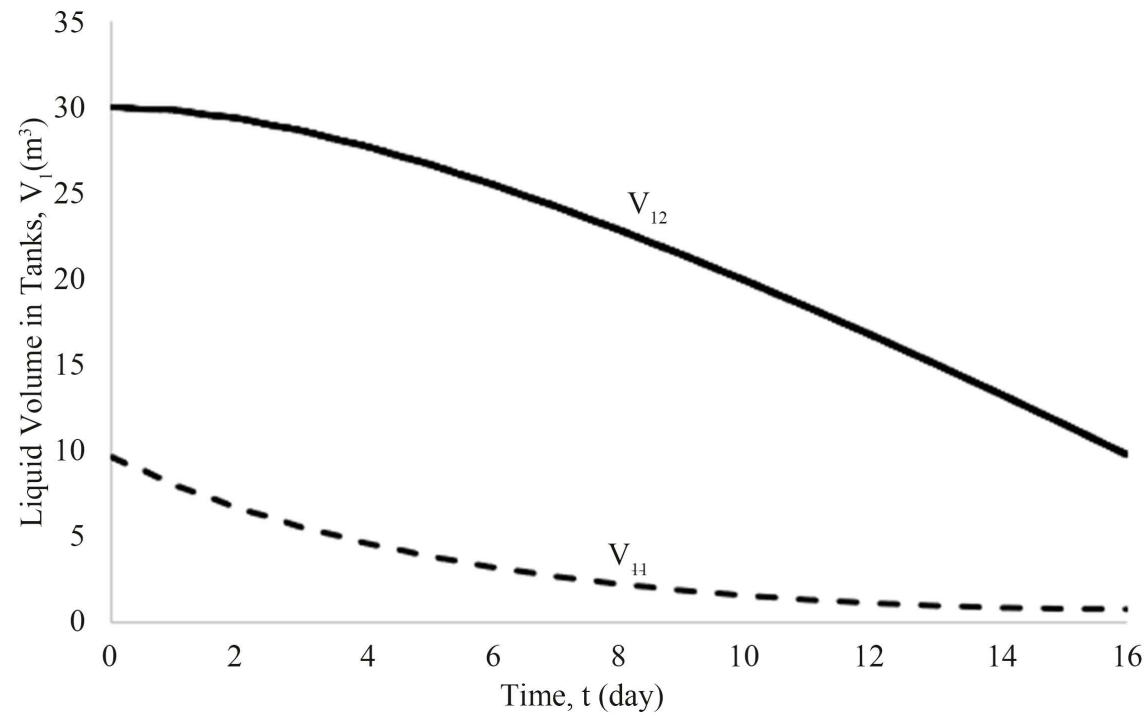

Figure 8. Temporal profiles of the liquid content of the two tanks.

the conventional single tank configuration.

\subsection{Parametric Study of Temperature}

An important application of the methodology developed in this study is in parametric study for optimizing the operation of an existing system or designing a new system. Using the proposed approach, the analysis of a system over a wide range of configurations and operating conditions is relatively fast and inexpensive compared to running experiments on a physical set up. For example, to see the effect of temperature variations, three types of temperature amplitudes $(10,20$, and 30 degrees centigrade) were compared, using the same temperature functionality given by Equation (27). The time profiles of inlet concentration, $C_{i n}$, mixing function, $b(t)$, and liquid volumes, $V_{l 1}$ and $V_{l 2}$ are shown in Figures 9-11, respectively. Results in Figure 9 show that a larger temperature variation results in a larger variation in the impurity concentration, primarily due to a larger effect of adsorption and desorption; it will also increase the extent of 


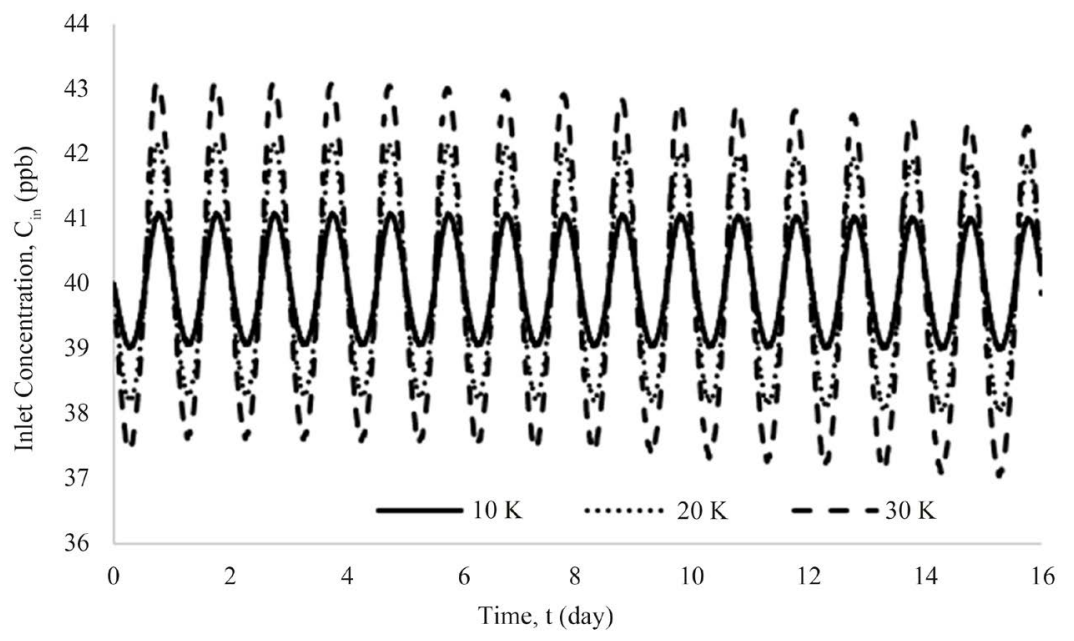

Figure 9. Temporal profiles of $C_{i n}$ under various temperature amplitudes.

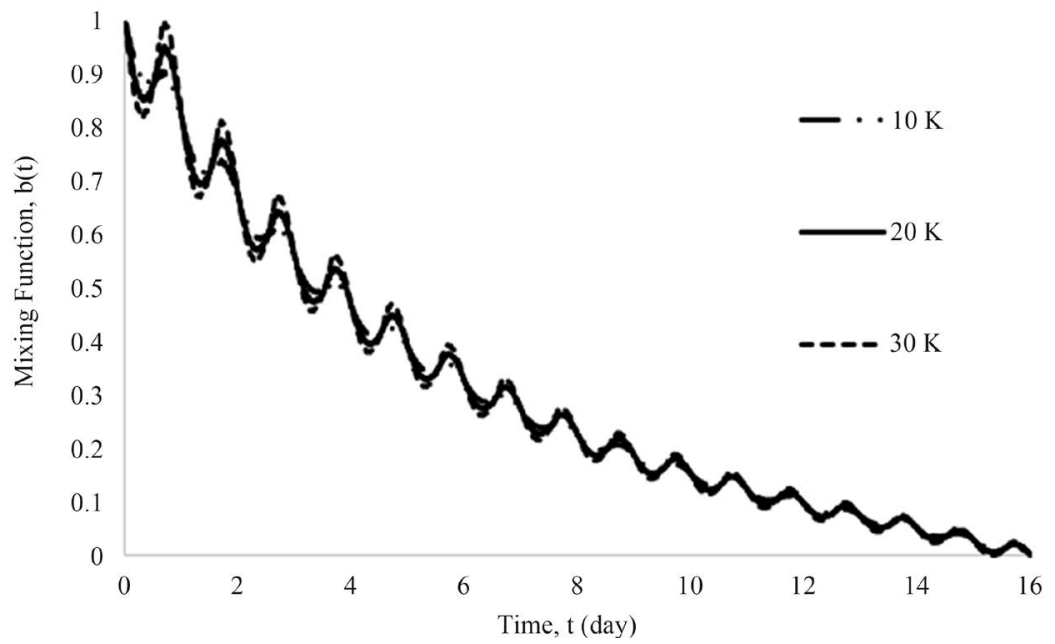

Figure 10. Temporal profiles of mixing function $b(t)$ under various temperature amplitudes.

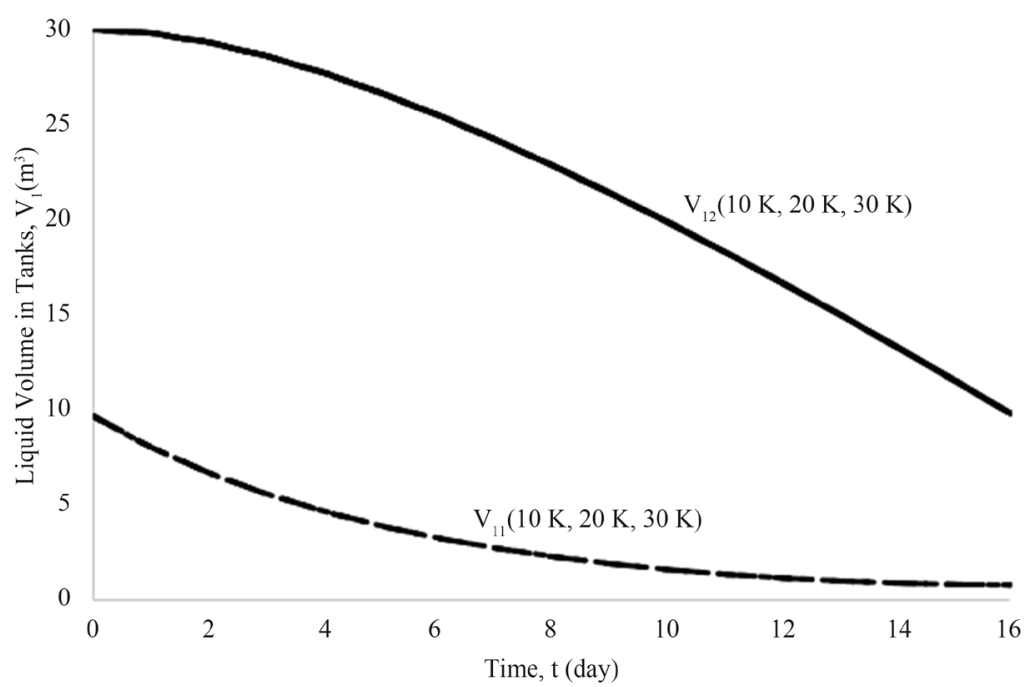

Figure 11. Temporal profiles of liquid content under various temperature amplitudes. 
change in the mixing function, $b(t)$.

\section{Conclusions}

Most semiconductor fabrication processes are very sensitive to impurities in purge and process gases. Therefore, maintaining a stable purity level in gas supply systems is of critical importance for this industry. Moisture is one of the most common and also most problematic impurities in the ultra-high-purity gases. Most UHP gases are supplied from cryogenic storage tanks and transported to the point of use (POU) by pipelines that are exposed to ambient environment. This arrangement results in variations of moisture level delivered to the POU due to two primary factors: The first is the drift due to the phase segregation of impurities during liquid vaporization in the cryogenic tanks. Moisture in most cryogenic systems segregates favorably in the liquid phase. This results in the retention and accumulation of moisture in the liquid phase and a gradual increase in the impurity in the gas delivered from these sources. The second factor is the variation of the impurity due to the adsorption and desorption on the surfaces of transport pipelines exposed to the varying outside temperature.

In this study, a new approach is proposed and analyzed that will cancel the variations caused by both of these two factors. In this approach, the stability and high purity at the POU are achieved through controlled mixing of gases from two cryogenic tanks. The mixing ratio is a dynamic function of time that is found through the application of a process simulator developed in this work. The simulator includes both the system geometry and configuration as well as the operating conditions and variations of external factors such as the ambient temperature. The proposed approach is expected to result in significant savings in the usage of gases. For example, compared to the conventional single-tank method, which can only use less than $80 \%$ of liquid nitrogen from a liquid nitrogen tank, the proposed method increases the liquid nitrogen utilization to over $90 \%$.

The formulation of the simulator is generally valid for most cryogenic gas supply systems. However, the continuation of this work should include application to the control of impurities in reactive gases such as moisture in ammonia, which is another key issue in the semiconductor fabs.

\section{Acknowledgements}

Financial and technical supports from Intel Corporation and the SRC Engineering Research Center for Environmentally Benign Semiconductor Manufacturing are acknowledged.

\section{Conflicts of Interest}

The authors declare no conflicts of interest regarding the publication of this paper.

\section{References}

[1] Watanabe, T., Funke, H.H., Torres, R., Raynor, M.W., Vininski, J. and Houlding, 
V.H. (2003) Contamination Control in Gas Delivery Systems for MOCVD. Journal of Crystal Growth, 248, 67-71. https://doi.org/10.1016/S0022-0248(02)01889-4

[2] Fine, S.M., McGuire, J.T., Choi, B.S., Bzik, T., Crofton, K.T., Melnyk, A., Perez, M. and Sheriff, D.P. (1996) Optimizing the UHP Gas Distribution System for a Plasma Etch Tool. Solid State Technology, 39, 71-77.

[3] Haider, A.M. and Shadman, F. (1991) Desorption of Moisture from Stainless Steel Tubes and Alumina Filters in High Purity Gas Distribution Systems. IEEE Transactions on Components, Hybrids, and Manufacturing Technology, 14, 507-511. https://doi.org/10.1109/33.83935

[4] Krishnan, S. and Laparra, O. (1997) Contamination Issues in Gas Delivery for Semiconductor Processing. IEEE Transactions on Semiconductor Manufacturing, 10, 273-278. https://doi.org/10.1109/66.572082

[5] Yao, J., Wang, H., Dittler, R., Geisert, C. and Shadman, F. (2010) Application of Pressure-Cycle Purge (PCP) in Dry-Down of Ultra-High-Purity Gas Distribution Systems. Chemical Engineering Science, 65, 5041-5050. https://doi.org/10.1016/j.ces.2010.06.002

[6] Ma, C. and Verma, N. (1998) Moisture Drydown in Ultra-High-Purity Oxygen Systems. Journal of the IEST, 41, 13-15. https://doi.org/10.17764/jiet.41.1.ym44t93qn5467505

[7] Ishihara, Y., Kurihara, S., Ishihara, S., Toda, M. and Ohmi, T. (1997) Trace Moisture Adsorption onto Various Stainless Steel Surface. Hyomen Kagaku, 18, 557-563.

[8] Dittler, R., Shadman, F., Guzman, R. and Muscat, A. (2014) Reducing Ultra-High-Purity (UHP) Gas Consumption by Characterization of Trace Contaminant Kinetic and Transport Behavior in UHP Fabrication Environments, ProQuest Dissertations and Theses.

[9] Vininski, J., Yilcelen, B., Torres, R. and Houlding, V. Bulk Specialty Gas Systems for Ammonia Gas Phase Delivery vs. Liquid Phase Delivery. http://www.mathesongas.com/electronics/technical-library

[10] Wu, J. and Shadman, F. (2018) Impurity Drift and Variations in High-Purity Gas Delivery Systems. International Journal of Engineering and Mathematical Modelling, 2018, 1-9.

http://www.orb-academic.org/index.php/journal-of-engineering-modelling/issue/vi ew/44

[11] Waldram, S.P. (1985) Non-Ideal Flow in Chemical Reactors. In: Waldram, S.P., Ed., Comprehensive Chemical Kinetics, Elsevier, Amsterdam, Vol. 23, 223-281.

https://doi.org/10.1016/S0069-8040(08)70148-1 


\section{Nomenclature}

$\alpha$ : ratio of liquid to vapor densities;

$b(t)$ : mixing function;

$C_{0}$ : initial gas phase concentration in the pipeline, $\left(\mathrm{mol} / \mathrm{m}^{3}\right)$;

$C_{1}$ : outlet impurity concentration of the first cell, $\left(\mathrm{mol} / \mathrm{m}^{3}\right)$;

$C_{f-1}$ : inlet impurity concentration of the last cell, $\left(\mathrm{mol} / \mathrm{m}^{3}\right)$;

$C_{f}$ : outlet impurity concentration of the last cell, $\left(\mathrm{mol} / \mathrm{m}^{3}\right)$;

$C_{i-1}$ : inlet impurity concentration of cell $i,\left(\mathrm{~mol} / \mathrm{m}^{3}\right)$;

$C_{i}$ : outlet impurity concentration of cell $i,\left(\mathrm{~mol} / \mathrm{m}^{3}\right)$;

$C_{i n}$ : inlet impurity concentration of the first cell, $\left(\mathrm{mol} / \mathrm{m}^{3}\right)$;

$C_{l 1}$ : impurity concentration of the liquid phase in $\operatorname{tank} 1,\left(\mathrm{~mol} / \mathrm{m}^{3}\right)$;

$C_{s 1}$ : adsorbed concentration in the first cell, $\left(\mathrm{mol} / \mathrm{m}^{2}\right)$;

$C_{s f}$ : adsorbed concentration in the last cell, $\left(\mathrm{mol} / \mathrm{m}^{2}\right)$;

$C_{s i}$ : adsorbed concentration in cell $i,\left(\mathrm{~mol} / \mathrm{m}^{2}\right)$;

$C_{s 0}$ : initial adsorbed concentration, $\left(\mathrm{mol} / \mathrm{m}^{2}\right)$;

$C_{t}$ : mixed concentration, $\left(\mathrm{mol} / \mathrm{m}^{3}\right)$;

$C_{t 1}$ : impurity concentration of the vapor phase in tank $1,\left(\mathrm{~mol} / \mathrm{m}^{3}\right)$;

$C_{t 10}$ : initial impurity concentration of the vapor phase in tank $1,\left(\mathrm{~mol} / \mathrm{m}^{3}\right)$;

$C_{t 2}$ : impurity concentration of the vapor phase in tank $2,\left(\mathrm{~mol} / \mathrm{m}^{3}\right)$;

$C_{t 20}$ : initial impurity concentration of the vapor phase in tank $2,\left(\mathrm{~mol} / \mathrm{m}^{3}\right)$;

d: pipe diameter, $(\mathrm{m})$;

$E_{a}$ : activation energy for the adsorption, (kcal/mol);

$E_{d}$ : activation energy for the desorption, ( $\left.\mathrm{kcal} / \mathrm{mol}\right)$;

$H$ : Henry's law constant;

$k_{a}$ : adsorption rate constant, $\left(\mathrm{m}^{3} / \mathrm{mol} \cdot \mathrm{s}\right)$;

$k_{a 0}$ : adsorption rate constant at $298 \mathrm{~K},\left(\mathrm{~m}^{3} / \mathrm{mol} \cdot \mathrm{s}\right)$;

$k_{d}$ : desorption rate constant, (1/s);

$k_{d 0}$ : desorption rate constant at $298 \mathrm{~K},(1 / \mathrm{s})$;

$L$ : pipe length, (m);

$M_{1}$ : total amount of impurity in tank $1,(\mathrm{~mol})$;

$P$ : pressure, $(\mathrm{Pa})$;

$Q$. volumetric flow rate, $\left(\mathrm{m}^{3} / \mathrm{s}\right)$;

$Q_{1}$ : flow rate from tank $1,\left(\mathrm{~m}^{3} / \mathrm{s}\right) ;$

$Q_{h}$ : high flow rate, $\left(\mathrm{m}^{3} / \mathrm{s}\right)$;

$Q_{l}$ : low flow rate, $\left(\mathrm{m}^{3} / \mathrm{s}\right)$;

$R$ : gas constant, $(\mathrm{J} / \mathrm{mol} \cdot \mathrm{K})$;

$S$ : surface area of each cell, $\left(\mathrm{m}^{2}\right)$;

$S_{0}$ : surface site density in each cell, $\left(\mathrm{mol} / \mathrm{m}^{2}\right)$;

$t_{h}$ : running time for high flow rate, ( $\left.\mathrm{min}\right)$;

$t_{l}$ : running time for low flow rate, (min);

$T_{0}$ : initial temperature in the pipe, $(\mathrm{K})$;

$T_{a}$ : ambient temperature in the pipe, $(\mathrm{K})$;

$V$ : cell volume, $\left(\mathrm{m}^{3}\right)$; 
$V_{g 1}$ : gas phase volume in tank $1,\left(\mathrm{~m}^{3}\right)$;

$V_{g 10}$ : initial gas volume in tank $1,\left(\mathrm{~m}^{3}\right)$;

$V_{g 2}$ : gas phase volume in tank $2,\left(\mathrm{~m}^{3}\right)$;

$V_{g 20}$ : initial gas volume in tank $2,\left(\mathrm{~m}^{3}\right)$;

$V_{l 1}$ : liquid phase volume in tank $1,\left(\mathrm{~m}^{3}\right)$;

$V_{l 2}$ : liquid phase volume in tank $2,\left(\mathrm{~m}^{3}\right)$;

$V_{t}:$ total tank volume, $\left(\mathrm{m}^{3}\right)$;

$V_{t 1}:$ total volume in tank $1,\left(\mathrm{~m}^{3}\right)$;

$Y_{g 1}$ : mole fraction of impurity in the vapor phase in tank 1;

$Y_{l 1}$ : mole fraction of impurity in the liquid phases in tank 1. 